\section{A study of couple communication patterns when coping with early stage breast cancer}

by B. Ann Hilton

\section{Abstract}

Talking patterns were explored in 43 couples where the woman was newly diagnosed with non-metastatic breast cancer. Family interviews were done at five points from the time of diagnosis to one year later. Qualitative grounded theory methods were used. Couples talked reasonably easily but in varying degrees about factual material. Three major types of couple talking patterns about fears, doubts and emotional issues were seen, based on whether they shared similar or different views about the importance of talking. Some couples talked openly or reasonably openly. Others did not talk to each other, although a few of these talked to other people. The third group of couples, who had divergent views, demonstrated more problems in their communication. Major reasons for talking/not talking patterns were related to prior patterns and beliefs, and to feeling that there was no need to talk or uncertainty about when, if and how to talk. The most facilitative communication pattern was open, but with selective disclosure. The findings have important implications for nursing.

"We handle stress differently. When I'm stressed out I kind of withdraw and get more quiet. When she gets stressed out, she compulsively talks and while she's compulsively talking I'm compulsively just trying to withdraw."

What happens to couple communication when a life-threatening diagnosis such as cancer strikes? How do couples talk to each other about the cancer and how open are they in sharing their concerns? Although communication is said to be vital to a satisfying family life (Bochner, 1976) little is known about the impact of life-threatening or chronic illness on these patterns and what types of communication help or hamper family coping. Further knowledge of this vital aspect of family processing would facilitate practitioners in their interaction with couples and families to assist in the adjustment process. Such knowledge would also facilitate the identification of couples who might need additional attention.

The purpose of this paper is to describe the methods and selected findings of a large longitudinal study of family adjustment to breast cancer where families were enrolled at the time of diagnosis and interviewed five times over a one-year period (Hilton, 1992, 1993). Because couple communication was noted as a particularly important family coping strategy, it is being presented as a separate paper. Space does not allow reporting of the findings for the total study in a single report. In this article, a synthesis is presented of the data provided by the couples during family interviews about their communication patterns, how those patterns changed and what influenced them. The specific research questions were: 1) How do couples talk about their cancer experience with each other? 2) What factors influence couples in their talking patterns? 3) How do couples' talking patterns change over time? and 4) Are particular communication patterns associated with greater satisfaction and functioning?

\section{Relevant literature and \\ conceptual framework}

Although early research generally links open disclosure of feelings, doubts, perceptions and fears with marital satisfaction and marital functioning (Boland \& Follingstad, 1987), more recent findings suggest selective disclosure is more effective (Flaherty, 1979; Schumm, Barners, Bollman, Jurich \& Bugaighis, 1986; Sillars, Weisberg, Burggraf \& Wilson, 1987). Many of the studies on couple communication have, however, been limited to couples coping with normal everyday circumstances or those undergoing counselling for marital discord. In addition, although little research has been done on family communication in life-threatening illness situations, the studies conducted indicate that family members have a tendency to engage in closed communication in terminally ill (Hinton, 1981; Krant \& Johnston, 1977-78; Stearns, 1986; Vachon et al, 1977), cancer recurrent (Chekryn, 1984), cardiac (Stern and Pascale, 1979), cancer (Thorne, 1977) and breast cancer situations (Jamison et al, 1978; Lichtman, 1982; Northouse, 1981). Interestingly however, from Lewis and Woods' study of family adjustment to breast cancer (1991), Zahlis and Shands (1990) found that only 11 of 67 partners of women diagnosed with breast cancer within the prior two-and-a-half years indicated difficulties in their struggle to communicate as a couple because of the cancer.

\section{UNE ÉTUDE DES SCHÉMAS DE COMMUNICATION AU SEIN D'UN COUPLE FAISANT FACE À LA PHASE PRÉCOCE DU CANCER DU SEIN}

\section{ABRÉGÉ}

On a étudié les échanges oraux de 43 couples où la femme venait de faire l'objet d'un diagnostic de cancer du sein non métastatique. Les entrevues familiales ont été effectuées à cinq reprises, du jour du diagnostic à un an après. On a utilisé des méthodes théoriques fondées sur l'étude qualitative. Les couples s'entretenaient assez facilement sur les faits, mais à des degrés différents. On a remarqué trois types importants de schémas de communication orale au sujet des craintes, doutes et questions affectives, selon que le couple avait des points de vue similaires ou divergents sur l'importance des échanges verbaux. Certains couples parlaient ouvertement ou assez ouvertement. D'autres ne se parlaient pas du tout bien que certains membres de ces couples en parlaient à des personnes de l'extérieur. Le troisième groupe de couples qui avaient des points de vue divergents, avaient plus de problèmes au niveau de la communication. L'existence ou la non-existence d'échanges verbaux venait des tendances et croyances déjà établies, et du fait qu'ils estimaient qu'ils n'avaient pas besoin d'en parler ou alors ils n'étaient pas sûrs s'il fallait oui ou non en parler, et quand, et comment. Le schéma de communication le plus ouvert dénote quand même une certaine sélection au niveau de la divulgation. Ces résultats ont des implications importantes pour les soins infirmiers.

B. Ann Hilton, RN, PhD, is associate professor, School of Nursing, University of British Columbia, Vancouver, B.C. 
Bowen (1976) and Silverman and Englander (1975) advocate open communication, in which members are relatively free to express feelings of sadness and loss as well as anger, guilt and relief. They believe that this is vital for the successful adjustment of family members and the family as a whole. Closed communication is believed to restrict the adjustment process and to increase tensions in the family system (Vess, Moreland \& Schwebel, 1985). For instance, when Vess and colleagues studied the link between communication and role enactment in cancer patients and their families, they found that spousal communication patterns influenced how well roles were enacted, the amount of role strain and role conflict and the level of cohesion or conflict in the family. Northouse also found higher levels of family expressiveness associated with better adjustment for mastectomy patients and their husbands (1988).

The conceptualization for this study was based on family stress theory and communication theory. Family stress theory identifies the adaptation process of a family to a stressful situation (Hill, 1949) and communication theory sees communication as a fundamental aspect of family process (Bochner, 1976). Communication assists people in creating and sharing meaning and thereby understanding others and being understood (Pearson 1989; Galvin \& Brommel, 1991). It consists of organization and the use of words, gestures, expressions, sounds and actions to create expectations, portray images, describe feelings and share meaning (Sedgwick, 1981). It involves a sender who transforms ideas and feelings into words or actions and transmits this message to a receiver. Although talking is the most commonly used method of transmitting messages, non-verbal behaviours such as facial expressions, eye contact, gestures, posture and spatial distance are also frequently used.

Factors influencing the process include the perceived need to communicate, personal characteristics, culture, attitudes, knowledge, environmental conditions, communication skills and past experience (Berlo, 1960). Identified barriers to effective family communication include power struggles, emotional dishonesty (lack of authenticity) and faulty assumptions and unreasonable expectations among family members, as well as problems with individual emotional and/or physical abilities (Sedgwick, 1981).

Because of its processing nature, communication is not static but develops and changes (Galvin \& Brommel, 1991). Families tend to adopt communication patterns which make life more predictable and manageable and thereby determine what, how, when and to whom to relate. Thus certain topics might be out of bounds for some families, whereas in others facts and ideas may be discussed, but feelings remain unexpressed.

\section{Methods}

The work reported here is part of a larger study. The larger study used a descriptive longitudinal correlational design which incorporated both quantitative and qualitative research methods. Family interviews were done in the home at the time of diagnosis and then three weeks, three months, eight months and 12 months post-surgery. Questions from the Problem-Centred Family Coping Interview were used to stimulate discussion (Lewis, unpublished material) as well as open-ended questions to reveal family experiences and talking patterns. All interviews were audiotaped unless otherwise requested (by two families). Transcribed interview data were subjected to content analysis and constant comparative analyses as explicated by Strauss and Corbin (1990). This technique involves carefully combing through and comparing transcripts of the interviews to establish patterns which could form the bases for categories. The categories integrated the data, but were broad enough to account for much of the variation. This method enables the researcher to describe and explain conceptual links among categories and to generate hypotheses for further thought and research. No attempt is made to control extraneous variables because the purpose is to describe talking patterns from the perspective of the women and their partners. A second coder verified the fit of the patterns. Discrepancies were resolved by revising the definition, recoding the unit or identifying new properties or categories.
In addition to the interviews, family members completed a set of standardized scales. Spouses completed the Couple Communication Scale (CCS) (Olson, 1985) and all family members over the age of 12 completed Spielberger's State-Trait Anxiety Inventory (STAI) (Spielberger, Gorsuch, Lushene, Vagg, \& Jacobs, 1983), the Family Crisis Oriented Personal Evaluation Scales (F-COPES) (McCubbin \& Thompson, 1987), FACES II (Olson, 1989) and the Family APGAR (Smilkstein, 1978). All scales had evidence of validity and reliability. Cronbach alpha internal consistency was satisfactory for this sample. Since the findings for this paper are based on the interview data, further detail will not be provided on the instruments at this time.

When women were diagnosed with stage 1 or 2 breast cancer and met the study criteria, they were asked by the surgeon, secretary or office nurse whether they would be willing to be contacted about a study on family adjustment to a breast cancer diagnosis. If they agreed to participate, a time for the first interview was determined. The same interviewer conducted all interviews for that family to establish rapport with the family and provide consistency. Admission criteria for the couple included that the woman was newly diagnosed with stage 1 or 2 breast cancer, had no prior cancer diagnosis and was younger than 75 . To participate, the families also needed to be able to read and converse in English. For the purposes of this study, family was defined as at least two people who are emotionally involved with each other and live in close geographical proximity.

The sample consisted of 41 families where the women were partnered. Fifty-four per cent of the couples were 36-55 years of age, $20 \%$ were $56-65,22 \%$ were over 65 and five per cent were $26-35$ years of age. This age breakdown was reasonably consistent with the age breakdown for those diagnosed with early stage breast cancer in British Columbia in 1986 (B.C. Cancer Registry, 1986). The couples had been together from one year to over 35 years. Although $20 \%$ had no children, almost half had adult children living elsewhere and $34 \%$ had children at home. Two-thirds of the women had partial mastectomy/lumpectomy and one-third had mastectomy. Twelve women had positive nodes. The majority $(n=25)$ had radiation therapy (RT) with 10 having both chemotherapy (CT) and RT. Three others had CT only and 13 women had tamoxifen or no further treatment. During the course of the first year, several women had further suspicious lumps investigated. For two of these women, it was a recurrence. One woman had reconstruction in the initial year. Although a few others considered reconstruction, others rejected the possibility outright. Two had prophylactic mastectomies on the unaffected breast. All the women were alive at the end of the first year; however, two of their husbands died rather unexpectedly just prior to or after the first year.

\section{Results}

The findings from each of the four research questions will be addressed in turn. The presentation of findings related to the first question about the talking patterns will include how couples talked about factual material and how they talked about their emotions, fears and concerns with each other. The three major talking patterns which emerged will be discussed: Couples who talked quite openly with each other; couples who did not talk much, if at all, to each other about their fears; and couples who displayed major problems in their talking patterns because one wanted to talk and the other did not. Major factors which seemed to influence these patterns will be described, followed by how the talking patterns changed over the course of the year. Which communication patterns seem to be more facilitative of family functioning will also be addressed. Quotes from the women and their partners will be included when appropriate to clarify and enrich the presentation of the above themes.

\section{How do couples talk about the cancer experience with each other?}

$A$ distinction was quite apparent between talking about content that was more factual and content that reflected emotions, fears, 
threats of recurrence, concerns and doubts. As one might expect, all couples talked in varying amount, depth and ease about concrete or factual things such as appointments, doctors' visits, what went on at the hospital/clinic, etc. Some talked about this in great detail, whereas others were more superficial, just talked about the "bare facts" or withheld information. For instance, one woman did not tell her husband her diagnosis for 18 days because she was concerned about his reaction. He later felt that she was withholding information, that is putting on an act and faking it, because she seemed so positive. He also believed that once you got cancer, you had a year to live "before it goes to the brain".

Although almost all couples talked about factual/concrete material, major differences were identified when it came to sharing fears/concerns, "the downside", the possibility of recurrence, other negatives and emotional issues. Three groupings of couples emerged fairly readily when these issues were explored. There were couples who talked openly or reasonably openly with each other about fears and concerns. They shared the view that it was important for them to talk together about the cancer and their fears. Then, there were couples who did not talk with each other. They shared the view that not talking about feelings with each other was important. Some of these couples talked to people other than their partner about concerns, but some did not. Another group stood out. These were couples in which one spouse felt it important to talk, but the partner felt it important not to talk. Their, communication was usually characterized by a pattern of talking past, through or around each other rather than with each other, and/or by a perceived lack of sensitivity and interest as displayed by verbal and non-verbal behaviour.

On the basis of these patterns, over half the couples ( $56 \%$ ) did not talk and only one-third did talk with each other about emotional issues related to the diagnosis ( $34 \%$ ). Of the 23 couples who did not talk, 13 did not talk to anyone else either, while 10 did talk with others. A further $10 \%$ of the couples seemed to have major talking problems. Each of these patterns will now be further described.

\section{Couples who shared the view that talking about fears was important for them}

Among the couples who shared the view that talking about fears and concerns was important, there were couples who talked quite openly with each other and couples who shared less and/or where the talking was more one-sided. In the more one-sided situations, however, the partner, who may not have been much of a talker, was willing to listen.

About half of the "talking" couples said they talked quite openly and discussed whatever bothered them about the cancer. They discussed sensitive topics with each other, talked openly in the interviews about fears and concerns and were generally active listeners. However, for them, talking did not necessarily mean they were open to sharing everything with each other and/or with their children. Some topics were not considered appropriate. In other words, while there were few areas they did not discuss with each other, having private thoughts and not sharing them was considered acceptable and not perceived as withholding or as uncaring. Although these couples thought they knew how each family member was feeling and that they had "short form ways" of communicating, they, more often than any group, were more likely to verify their perceptions. They were less likely to operate on assumptions alone. This assisted them in better understanding how the other was feeling. They were sensitive to each other and tried to be aware of other family members' feelings, often using humour in their interactions. They also seemed comfortable expressing verbal and non-verbal affection and talked about issues when they arose and tried not to let issues build. Usually, these couples had an open style of communication with their children, whether they were adult children living nearby or farther away or young children and adolescents living at home. However, although these couples were reasonably open in sharing with each other, they did not necessarily share a lot with their extended family or friends.

This pattern is reflected in the following example. The Browns have two adolescents. Although they did not spend hours and hours talking, a family member would generally approach another if something came up. The couple said they tried to be very clear about how they were feeling. rather than talking "around the cancer", and tried to be aware of how the

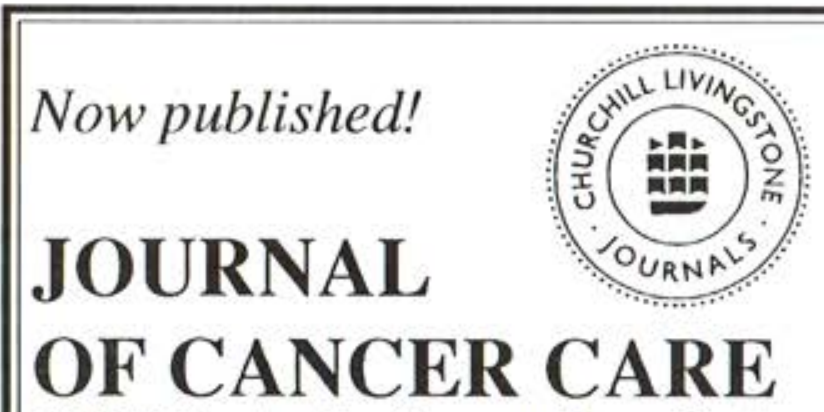

EDITORS: Ann Faulkner and Irene Scott

\section{THE JOURNAL OF CANCER CARE}

covers cancer care in hospitals, homes and hospices.

Prevention...early detection....acute, treatment-oriented care...continuing care...palliative care.

PLUS...rehabilitation...psychological care, care of family members, support mechanisms for formal and informal carers...psychological impact of illness and attitudes to cancer...oncology education in Europe and the rest of the world.

\section{CONTENTS OF FIRST ISSUE INCLUDE:}

Childhood cancer: psychosocial needs Are they being met?/G Peace, C O'Keefe, A Faulkner, J Clark Shared care in paediatric oncology/K R Muir. $S$ E Parkes, $R$ Boon, M C G Stevens, J R Mann Cancer Centre profile: The Christic Hospital/I Scott Quality of life/B M Traynor

Advances in symptom control for dysphagia and dyspnoca/N P Sykes

Health promotion:testicular self examination/M Johnson

\section{SUBSCRIPTION INFORMATION}

ISSN 0960-9768 4 issues Vol 11992

Member rate $\quad \$ 20$ (UK) $\$ 22.50$ (Eur/O's) $\$ 42.50$

(RCN, Cancer Relief Macmillan Fund and other nursing organisations)

Individual rate 149 (UK) $\$ 51.50$ (Eur/O's) $\$ 90$ (USA)

Institutional rate 879 (UK) 883 (Eur/O's) $\$ 145$ (USA)

\section{FREE SAMPLE COPY OFFER! \\ \&. - - - - - - - - - - \\ JOURNAL OF CANCER CARE}

Yes! Please send me a sample copy.

Name

Address

Postcode

Return to: Churchill Livingstone Journals

Robert Stevenson House

1-3 Baxter's Place, Leith Walk

92JCCKCANO EDINBURGH, EHI 3AF, Scotland, UK 
other felt and purposely delayed telling their adolescent children about the cancer for two days until one had finished with examinations and the other was home; the adolescents were best friends and the parents knew they would provide important support for each other.

Couples who listened and talked to each other about fears, but to a lesser degree than in the above example, or displayed a more one-sided pattern, where one talked while the other listened attentively, were considered "medium talkers". Some families claimed to talk openly, but on further observation, this was found to be inaccurate. If this was the case, they were reclassed as "medium talkers" when the content of their discussions reflected at least some attention to concerns and feelings. Some of these couples qualified their degree of openness in talking, stating, for example, that they operated on a "need to know basis" and that they had a "short form" way of being very clear about their feelings rather than talking around and around those feelings. These couples expressed affection somewhat less overtly than the "talkers". When they talked with their children about the cancer and cancer-related issues, they usually limited the discussion to factual material, avoiding emotional issues.

Receptivity to listening can facilitate effective communication, and this was noted in these talking patterns where both members believed talking was important. In situations where one was more the talker and the other more the listener, it was usually the woman who was the talker. Being open to listening, however, did not necessarily mean they were open all the time. One woman complained: "I've spilt my guts to him 'cause I don't want to burden a friend" [but] "I was getting sick and tired of hearing about how tired he was and how stressed out he was and whenever I didn't feel good he would come and say the same thing. This is not what I want to hear. When I tell you I'm tired or my stomach isn't feeling well, you're not supposed to tell me you're having the same problem."

\section{Couples who shared the view that not talking about fears was important}

Twenty-three couples $(56 \%)$ did not talk about feelings/concerns/fears and doubts with each other. They shared the view that not talking was important. Some of these couples directly stated that they avoided talking, but that did not mean that they were not close. Several of these couples commented on how close they were and a few said "being close does not mean sharing". A more restricted talking pattern was also evident with their children who were mostly adults living away from home. For instance, one "non-talking" husband said: "We certainly don't talk about any other risks - just to be factual helps. Factual means you stick to things and ask questions that have concrete answers rather than being philosophical or having some deep meaning or hypothetical consequences. We don't have those. We just have - how are you feeling? Are you feeling better? Does it hurt? Things that you can give a very plain yes-no answer to." One woman said: "I only say what he wants to hear so I was withholding stuff. I help him cope by not overloading him about how I feel - just leave it at the facts." A husband of another woman was concerned about his coping when he said during the interview with his wife present: "It's better she keep quiet, not say nothing 'cause that way there's nothing on my mind to think about this. To me, it's like she's already dead. I don't want to think no more about it,"

There were a number of couples $(\mathrm{n}=10)$ who did not talk together, but one or both felt comfortable talking to others about their emotional concerns. The majority of these couples were older than 55 years of age, whereas the talking couples were more likely to be younger than 55 .

Despite this, couples who share the view that not talking, or talking only about concrete matters, was important, exhibited less conflict

\section{Canadian Cancer Statistics Booklets}

The 1993 edition of the booklet Canadian Cancer Statistics was to be available in late September 1993. Breast cancer is highlighted as a special topic this year. The booklet will not be circulated with the CANO Journal to its subscribers. Instead, individuals can obtain copies at their local or divisional office of the Canadian Cancer Society. The phone numbers and addresses of local offices are listed in the white pages of telephone books. In addition, the addresses of the divisions of the CCS are listed in the booklet.

Copies of the booklet will also be available at regional offices of Statistics Canada and offices of provincial cancer registries (see page 60 of the 1992 edition).

With respect to the order form on the last page of the booklets, individuals will continue to be asked for their comments and addresses each year so that this mailing list will be updated on a yearly basis.

\section{Livrets "Statistiques canadiennes sur le cancer"}

La version de 1993 du livret "Statistiques canadiennes sur le cancer" est disponible depuis la fin du mois de septembre 1993.

Le cancer du sein y est souligné comme sujet spécial cette année. Ce livret n'est pas envoyé aux abonnés de la Revue de l'ACIO. Au lieu de cela, on demande aux personnes intéressées de se procurer des exemplaires auprès du bureau local ou du bureau divisionnaire de la Société canadienne du cancer. Le numéro de téléphone et l'adresse des bureaux locaux apparaissent dans les feuilles blanches de l'annuaire téléphonique. En plus, vous trouverez l'adresse des bureaux divisionnaires de la SCC dans le livret.

On pourra aussi se procurer des exemplaires du livret aux bureaux régionaux de Statistique Canada et aux bureaux des Registres provinciaux du cancer (voir la page 60 de l'édition de 1992).

Et en ce qui concerne le bon de commande figurant à la dernière page des livrets, on va continuer de demander aux particuliers de nous envoyer leurs commentaires et leur adresse tous les ans afin que nous puissions maintenir à jour notre liste d'adresses. 
than couples in the final category. This was reflected in their discussion generally and also discussion specifically related to their relationship.

\section{Couples with divergent views about the value of talking about feelings}

In addition to the couples who had shared views about the importance of talking or not talking were those who had views that diverged in a major or minor manner.

Those with major differences demonstrated the following characteristics: Varying levels of difficulty in their communication regarding what was said, how it was said and how it was interpreted, and problems related to their manner of talking or their unwillingness to listen or share. Often it was evident that the couple was plagued by unresolved problems which predated the diagnosis. For example, one husband to some extent was still blaming his wife for the death of their baby three years earlier.

In general, these couples exhibited greater insensitivity in their interactions than others did. They were occasionally very blunt and unselective about their thoughts and stated them without apparent recognition of how these might be received. One couple, for example, "did not hide anything" from their 10-year-old son, exposing him to their frequent arguments and put-downs of one another. Another major difference between them and others was that one or both of them felt unsupported by the other. Not talking was, in some cases, interpreted as a lack of caring. Non-verbal behaviours were also identified or misinterpreted as uncaring, as illustrated by one woman's complaint that her husband did not come home every night and kiss her to illustrate that he was "glad for her to be alive". Initially, two husbands in this group even talked about the need to think of getting another wife.

The following example of a young couple with a young child reflects some of the confusion and frustrations created by problems with talking and with interpreting the talking which led to a feeling of lack of support. Early in her cancer diagnosis, she said: "We didn't communicate. He was keeping it all to himself, didn't want to talk and was avoiding it, whereas I had to talk. I would have to bring it up to him." She talked to others and he wondered why she talked to the people she did. When he told a friend that he needed release from being positive at home, his friend told him he "should be positive all the time". He had great difficulty when his wife expressed negative thoughts because she was supposed to be trying to feel and show optimism. When she said: "I'm allowed to have negative feelings and down days," he said: "No. You can't. You're very positive. If you're positive, you're positive. If you're negative, you're negative." He basically did not talk about his fears, but when he did express concerns that things might not turn out well, she became very upset. Following her chemotherapy and radiation therapy, he continued not to want to talk and wanted them to get on with their lives because "it had been fixed". She continued to infer that his not wanting to talk reflected a lack of caring.

The couples who reflected more moderately divergent views than those described above showed less problematic communication patterns and had less difficulty. There may have been minimal sharing or the situation may have reflected one member talking with the partner having considerable difficulty listening, although still very supportive. The quote at the beginning of this paper reflects a couple who used this pattern. Caring was obvious in these couples, but sharing was not without some difficulty.

\section{What factors influenced their current talking patterns?}

Throughout the transcripts, the investigator identified many factors which seemed to influence the talking patterns: The age of the couple, prior patterns of communication, beliefs about talking, perceptions about the need to talk and difficulty because of their uncertainty about when, if and how to talk.
Generally, older couples were more likely not to talk to each other about their feelings while the younger couples were usually more open about their fears. However, the youngest couples were most likely to display patterns that reflected discrepant views. Women were more likely to want to talk than not talk in situations where there were differing views within the couple.

Prior patterns of the couple's interaction were usually reflected in their current sharing patterns about the cancer situation. When talking had been quite open prior to the diagnosis, couples generally continued to be open, and where talking had been fairly limited, the pattern was likely to continue: "I don't tend to verbalize those things", "We don't get into each other's heads. We're not into this psycho stuff."

Shifts in patterns from normal were usually temporary. Couples who displayed major discrepancies in their views about talking and showed major difficulties usually had prior marital discord and unresolved issues. There were a number of beliefs that seemed to influence their talking patterns, including that talking was negative, that it tempted fate and that it would not help: "To talk is to dwell and to dwell is negative. The more you go into the ramifications of what's going on in your mind, the worse off your mind's going to get." In addition, talking about it was not considered normal and was seen to prevent a return to normality. One woman said: "I don't want it brought up in my face all the time. I want us to get back to our normal way of life because I think something that is brought up and kept bringing up that you don't get a chance to heal from it." Another woman reflected a similar perspective: "I'd rather you still want to come home and not be thinking, 'Oh God. I'm going to have to go home and listen to a whole tirade of how the day went or how the cancer's coming or how the treatment's going.' I'd rather still have you come home to as normal a situation - compared to the fact that it's not normal. Things just are not the norm right now. I mean, I'm trying to make it so you don't dread coming home."

Many indicated that talking about the cancer was uncomfortable and comments reflected the extent of this belief. One woman said: "Talking about cancer makes me sick!" Another said: "I was avoiding talking too much because I didn't want to upset him or myself." One husband stated: "It can be a horrible illness." His wife then asked the interviewer: "Would you really want to talk about it when he does this?... so it's best just to forget it." She said she had to get after him several times because he made her feel so bad. On the other hand, another husband said he did not say what he really felt, "seeing her in so much pain and her being fearful of what yet may come. Next thing you know, it's liver cancer so the worse could even be worse and I know that is going through her mind so I really feel bad for her, so I have to say, 'Great - we're going to go on and we'll be off doing our thing in three or six months'." He also said that he would read about cancer, but would only tell her some of what he read. She said he instilled a great deal of confidence in her. There were many other examples of how not talking was seen as serving as a protective function for one or both members.

Although not common, a few couples said that cancer or its effects were not topics that should be talked about because they were personal matters. "There are just some things we don't discuss out of mutual respect - they are private." For still others, talking implied not being able to manage. For many couples, not talking helped to minimize the situation.

Although many couples found it important to talk, couples classified as non-talkers found it important not to talk. Some said there was no need to talk because there was nothing to talk about. This was particularly noted when treatments were finished and side effects were gone or minimal. Some said they didn't talk because they didn't see the cancer as fatal. Others felt that it was out of their hands and, in this case, they had usually given it over to the Lord. Many couples, however, said that there was no need to talk because they knew how the other felt without talking, since they had been together so many years and therefore knew each other. An interesting difference between non-talkers and talkers, however, on this point, was that talkers were more likely to say they still needed to validate 
their perceptions with their partner.

Although not mentioned frequently by the couples, another factor that influenced the pattern of communication was uncertainty about when, if and how to talk. When this occurred, they usually remained silent. "I don't know whether I should be bringing it up or just letting it go." Another husband took cues from his partner and if she didn't talk, then he wouldn't either. "I think it's really on the back burner right now for me primarily because [she] doesn't talk about it so I have the same notion [that] things are okay, but I have the fears once in a while."

\section{How do couples' talking patterns change over time?}

Initially, the couples had obvious reasons to talk about the cancer, its implications and their fears and concerns because they were confronting it on a daily basis. They had decisions to make, and they had to cope with tests, treatments, side effects, appointments with doctors, and so on. There were many "factual, concrete" topics to talk about in addition to the emotional issues which they and others recognized as major at that time.

As the rigours of the diagnostic and treatment phases ended, the need to talk was perceived to have lessened. This was also perceived by those couples considered to be talkers. Many did not talk much about it with each other when the treatments were finished; however, the subject arose again when check-up times approached. A few commented that they had not talked about it since the prior interview. Although the majority did not talk much beyond the treatment phase, several individuals commented on still wanting to talk about it to some degree. Several people, usually the women, commented on the helpfulness of the interviews because it gave them a forum to talk since the topic didn't usually come up in conversation, but they still needed to talk. This was not restricted to only the "non-talking" families. This illustrates that although some couples may not talk, not talking does not necessarily reflect that couples or individuals did not want to talk or did not still see a need to talk.

The importance of talking about the cancer and their concerns was heightened considerably when unusual events occurred or events were seen as threatening. Recurrence brought the threat of their situation dramatically back to the forefront for these families. Making decisions about reconstruction or talking about further breast lumps sometimes precipitated further discussion of their concerns and the situation. The media which emphasized cancer issues was a constant reminder for them and many perceived that there must have been a media blitz on breast cancer. Some couples were open to talking with people other than their partner about their experience whereas others were not. Some wanted to bury it and although they might readily talk about other illnesses, surgery or events that had occurred with themselves and others, their cancer experience was often seen as completely different with completely different rules.

\section{Are particular couple communication patterns associated with greater satisfaction and functioning?}

Outcomes from the different sharing patterns included knowing where their partner "was at", being "in sync", satisfaction with their sharing patterns and their relationships, satisfaction with their adjustment and the anxiety of family members.

Couples who shared reasonably openly said it made their coping easier "once you verbalize things... you immediately feel the load lifted", "hiding things - keeping things bottled up is not good." These couples were "in sync" with each other. They knew where the other was "at" and they felt that the other knew where they were "at" and were generally very satisfied with their communication. Although "medium" talker couples were generally satisfied with their communication, their satisfaction was not as consistent nor to the same degree as that of the above.

When couples had limited disclosure, neither member necessarily had all the information they needed to make accurate judgments. At times, they acted on information they thought was accurate, but was based on assumption, incomplete information, or their own beliefs and expectations. Although these non-talking couples were often satisfied with not talking, some said they really didn't know how their partner felt and that this impacted on their relationship. Lower levels of communication and the subsequently poorer exchange of information caused problems for several couples. In some cases, members were kept in the dark, which was often problematic. When sharing patterns had not been open, expression of feelings was often difficult for other members to cope with generating guilt.

Families who had extremely divergent views generally had much poorer assessments of their talking patterns, frequently proving quite dissatisfied. One couple, for example, had initially been quite satisfied while they "cocooned" and put their other issues on the shelf. However, as soon as she regained "the strength to argue", their prior dissatisfying patterns re-emerged. Not surprisingly, most of these couples felt a lack of support from the other. "Family members seemed to be going their own way." Even couples with less divergent views who had temporary periods of initial non-sharing displayed some dissatisfaction with their communication.

\section{Discussion}

The findings of this study indicate that all couples talked about "concrete" matters related to the cancer diagnosis in varying degrees, but fewer than half talked with each other about their feelings, fears, doubts and concerns regarding the cancer. Of those who did not share with each other, a considerable number did share their burdens with people other than their partners. Minimalization and some distortion of how they felt was reasonably common. Minimalization of sharing through talking by some couples may be surprising but understandable because they were trying to protect themselves and their partners.

Although many couples talked about being open, many of these same couples were not open to sharing concerns, fears and doubts about the cancer with each other. These findings coincide with Shapiro and Swenson's (1969) in which husbands and wives over-estimated how much they disclosed to each other. Shapiro and Swenson, however, suggested that it is the perception of disclosure that may be more important than the amount of disclosure.

Gottman (1979) holds that the importance of self-disclosure may be overrated. Although many couples in this study emphasized their need to talk, others were equally as emphatic about the need not to talk. A situation which implies a life threat such as a diagnosis of cancer emphasizes vulnerability for the individuals and the family. Self-disclosure emphasizes vulnerability because it requires the person to risk sharing his or her personal thoughts and private feelings to another, thereby rendering them vulnerable to the other and to the situation. Glaser and Strauss (1968) have noted the pattern of not talking in families when everyone is aware that the others have feelings but no one knows how to talk about them and prefers that others keep their feelings to themselves. Vess and colleagues (1985) refer to this as a conspiracy of silence. Although there are advantages to a conspiracy of silence, difficulties and increased family tension can develop when decisions and role expectations are made on the basis of assumptions rather than on explicit communication (Bruhn, 1977).

Equity theory predicts that individuals maintain a balance by exchanging comparable behaviours so that when one person discloses information, the other reciprocates (Walster, Walster \& Berscheid, 1978). In this way, levels of self-disclosure are similar for the couple - if one person shares, the other is more likely to be open, whereas if one does not talk, the other is also not likely to share. Walster et al found that patterns of communication are perpetuated and strongly influenced by prior patterns in the couple, in the families of origin, and in the culture and by beliefs. This was also the case in these couples.

A number of partners did not share their concerns because of a concern for how those feelings would impact on the other. As such. 
it was done to protect the other and themselves from additional stress and to maintain emotional control. This avoidance is a normal coping mechanism for individuals dealing with life-threatened loved ones (Degner, Beaton and Glass, 1981; Vachon et al, 1977). Such avoidance has been reported in families with terminally ill members for similar reasons (Stearns, 1986). Stearns suggested that avoidance is an expression of affection towards the patient, a caring, deliberate decision to be selective in interpersonal communication and that there was little evidence to suggest that decreased verbal sharing, while distressing to the spouse, was detrimental to the husband-wife relationship.

Although many couples were very honest in revealing their feelings and beliefs, others used minimalization and distortion to protect their partner from their true feelings. Prior research supports the use of selective distortion, privacy and secrecy in providing relief when contact becomes too intense or involved (Schwartz, 1968) and in promoting intimacy by allowing one to protect others, by helping to maintain a focus in conversations, and by aiding in avoiding tension and conflict (Turner, Edgley and Olmstead, 1975). Parks (1981) indicated that there was no real research basis for prescribing complete openness and honesty in interpersonal relationships and suggested that a certain amount of deception, privacy and secrecy characterized many intimate relationships. Davidson, Balswick and Halverson (1983) found that individuals with high levels of marital adjustment used selective distortion in an apparent attempt to eliminate distress from their relationships more than those with low levels of marital adjustment. This finding was corroborated by Beach and Arias (1983) who suggested that positive distortion may be a healthy and useful aspect of a well-functioning marriage. In addition, discriminating disclosers were more satisfied than indiscriminating disclosers and Bochner stated that people in long-term relationships cannot afford to disclose totally openly because they have too much to lose (1981).

Many couples in this study talked about knowing how the other felt without talking because of the longevity of their relationship. Although indirect communication such as through intuition, habit and observation rather than through conversation is not unusual (Gottman, 1979), problems can and did occur when inaccurate assumptions were made. The couples which acknowledged a need to validate their assumptions because of the possibility of inaccurate assumptions were primarily couples who enjoyed more open talking patterns. However, when a caring and supportive atmosphere was established, either verbally or non-verbally, verbal confirmation was no longer seen as important. One member of a supportive couple expressed this well when she said: "You don't talk emotions, you feel emotions."

Families often have topics which are taboo. Baxter and Wilmot (1985), who studied families in non-illness situations, identified the following topics as taboo: State of the relationship, extra-relationship activity, relationship norms, prior relationships, conflict-inducing topics and negatively valenced self-disclosure. Death and dying are often taboo (Feifel, 1977). Because of the life-threatening nature of the situation in this study, some families considered the discussion of fears and concerns about the cancer as something they shouldn't talk about.

A noteworthy number of couples, approximately $10 \%$, seemed to have considerable difficulty in their communication and this was usually accompanied by considerable difficulty in their marital relationship, as identified by them and by their reaction to the cancer, illustrating the importance of effective communication to a relationship. This was particularly noticeable if the woman did not feel she was being understood and supported. In these couples, there was a major component of negativity to their communication, a lack of congruence as to the need for talking, a talking past, through or around each other rather than with each other, and/or a perceived lack of sensitivity and interest in the partner as displayed by verbal and non-verbal behaviours. The above was either stated directly or indirectly by the couples in the interviews.

\section{Summary and implications}

In summary, the data from these couples coping with early stage breast cancer suggests patterns in couple verbal communication. Whether these same patterns would be seen in different couples coping with similar or different stage cancers needs further exploration, as does the contribution of non-verbal interaction. In addition, one must be cautious about generalizing the findings from this sample to all couples coping with early stage breast cancer. Given these limitations, however, the data hold implications for nursing practice.

When it comes to talking about concrete and factual matters, couples generally talk with relative ease. However, when it comes to talking about fears and emotions, communication seems much more difficult. Given the high ratio of "non-talking" to "talking" couples in this sample, couples seem more likely not to talk about their fears and emotions related to the cancer experience than they are to talk with each other. It is likely that some couples have particular difficulties in their communication. Spouses who don't talk to their partner may still, however, want and need to talk to people other than their partners. Factors that seem to influence talking patterns include prior talking patterns, beliefs about talking, the perceptions of the need to talk and uncertainty about when, how and whether to talk. For the most part, couples tend to talk less about the cancer as time passes. Reasonably open but selective disclosure seems to be the most facilitative communication pattern, whereas couples with divergent communication needs have the greatest difficulties.

These findings suggest that as nurses and health professionals, we may assume that couples talk more to each other about their fears and concerns than they actually do. Also, while health care professionals commonly assume that openness is essential, this research suggests that such openness exists in only a few families. In fact, some couples may prefer to remain silent, seeing not talking, minimizing or distorting as helpful because to them it reflects concern and protectiveness. This shows that we must carefully assess each situation to determine the pattern and quality of interaction and how well that pattern is working for that family. Some families may be communicating and functioning well, while others may need assistance in sharing issues and concerns with each other and/or being more aware of how the other is feeling. The most important consideration, however, seems to be whether the couple's perceptions of what is important in their communication agree.

Providing opportunities for sharing can assist couples in their communication and thereby facilitate adjustment. Many couples talked about how helpful the interviews had been by giving them an opportunity to talk about their concerns together and how, through this they had become more aware of how their partner was fecling. This indicates that encouraging partners to accompany their wives to appointments is helpful because both will hear the same information and will have better opportunities to talk in an environment that may be seen as safer for talking.

Although opportunity for sharing within the couple is helpful, it may be particularly important for some individuals to share with someone other than their partner. Participation in cancer support groups, particularly those geared to the breast cancer concerns, can provide an alternate avenue for effective sharing. The opportunity for men to share their concerns together might also be helpful for some.

\section{Recommendations for research}

This paper concentrated on the communication patterns of couples coping with early stage breast cancer. Further reports from this study about communication patterns will address total family interaction including the children and the responses by the couples to the Couples Communication Scale. Many areas can be identified for further research in this area. Although some families which participated in this study had children, there is a need for further study about how children communicate when a parent has cancer. In addition, this study limited itself to communication patterns where the woman was diagnosed with early stage breast cancer. Although it is likely that 
sharing patterns will not reflect major differences if more extensive cancer is initially diagnosed, further research is needed in this area. Similarities and differences in patterns should be explored when the man is diagnosed to have cancer. Further research on families would benefit from including individual and family interviews. A combination of such approaches would provide a fuller perspective to a complex subject needing further study.

\section{References}

1. Baxter, L.A., Wilmot, W.W.(1985). Taboo topics in close relationships. Journal of Social and Personal Relationships, 2, 253-269.

2. Beach, S.R.H., Arias, I. (1983). Assessment of perceptual discrepancy: Utility of the primary communication inventory. Family Process, 22, 309-16.

3. Berlo, D.K. (1960). The process of communication. New York: Holt, Rinehart \& I Winston.

4. Bochner, A.P. (1981). On the efficacy of openness in close relationships. In M. Burgoon (Ed.), Communication Yearbook 5 (pp.109-124). New Brunswick, NJ: Transaction Books.

5. Boland, J.P., Follingstad, D.R. (1987). The relationship between communication and marital satisfaction: A Review, Journal of Sex and Marital Therapy, 13(4), 286-313.

6. Bowen, M. (1976). Family reaction to death. In P. Guerin (Ed.), Family therapy. New York: Gardner Press.

7. Bruhn, J.G. (1977), Effects of chronic illness on the family. Journal of Family Practice, 4(6), 1057-1060.

8. Chekryn, J. (1984). Cancer recurrence: Personal meaning, communication and marital adjustment. Cancer Nursing, 7, 491-8.

9. Davidson, B., Balswick, J., Halverson, C. (1983). Affective self-disclosure and marital adjustment: A test of equity theory. Journal of Marriage and the Family, 45, 93-102.

10. Degner, L.F., Beaton, J.I., Glass, H.P. (1981). Life-death in health care: A descriptive theory. Winnipeg: University of Manitoba, School of Nursing,

11. Feifel, H. (1977). New meanings of death. New York: McGraw-Hill.

12. Flaherty, J.A. (1979). Self-disclosure in therapy: Marriage of the therapist. American Journal of Psychotherapy, 33, 442-452.

13. Galvin, K.M., Brommel, B.J. (1991). Family communication: Cohesion and change. (3rd ed). New York: Harper Collins Publishers Inc.

14. Glaser, B.B., Strauss, A.L. (1968). Time for dying, Chicago: Aldine Publishing.

15. Gottman, J.M. (1979). Marital interaction: Experimental investigations. New York: Academic Press.

16. Hill, R. (1949). Families under stress. New York: Harper and Row. 17. Hilton, B.A. (1992). Longitudinal family adjustment to a breast cancer diagnosis - preliminary report for B.C. Health Research Foundation.

18. Hilton, B.A. (1993). Issues, problems, and challenges for families coping with breast cancer. Seminars in Oncology Nursing, 9(2), 88-100.

19. Hinton, J. (1981). Sharing or withholding awareness of dying between husband and wife. Journal of Psychosomatic Research, 25, 337-343.

20. Jamison, K., Wellisch, D., Pasnau, R. (1978). Psychosocial aspects of mastectomy: 1. The woman's perspective. American Journal of Psychiatry, 135(4), 432-36.

21. Krant, M.J., Johnston, L. (1977-1978). Family members' perception of communication in late stage cancer. International Journal of Psychiatric Medicine, 8, 203-216.

22. Lewis, F.M., Woods, N.F. (1991). Final report: Family functioning in chronic illness, Volume II, University of Washington.

23. Lichtman, R. (1982). Close relationships after breast cancer. Unpublished doctoral dissertation. Los Angeles.

24. McCubbin, H.I., Thompson, A.I. (Eds.) Family assessment inventories for research and practice. University of Wisconsin-Madison.

\section{Acknowledgements}

The author wants to express appreciation to the co-principal investigator Dr. Patricia Rebbeck, to the surgeons and the office staff for their involvement in recruitment, to the members of the research team and to the families who participated in the study. This research was supported by the B.C. Health Research Foundation.

25. Northouse, L. (1981). Mastectomy patients and the fear of cancer recurrence. Cancer Nursing, 4(3), 213-220.

26. Northouse, L. (1988). Social support in patients' and husbands' adjustment to breast cancer. Nursing Research, 37(2), 91-95.

27. Olson, D. (1989). FACES II manual - personal communication.

28. Parks, M.R. (1981). Ideology in interpersonal communication: Off the couch and into the world. In M. Burgoon (Ed.), Communication Yearbook 5 (pp. 79-107), New Brunswick NJ: Transaction Book.

29. Pearson, J.C. (1989). Communication in the family: Seeking satisfaction in changing times. New York: Harper \& Row.

30. Schumm, W.R. (1983). Theory and measurement in marital communication training programs. Family Relations, 32, 3-11.

31. Schumm, W.R., Barnes, H.L., Bollman, S.R., Jurich, A.P., Bugaighis, M.A. (1986). Self-disclosure and marital satisfaction revisited. Family Relations, 34, 241-247.

32. Schwartz, B. (1968). The social psychology of privacy. American Journal of Sociology, 73, 741-52.

33. Sedgwick, R. (1981). Family Mental Health: Theory and practice. St. Louis: C.V. Mosby.

34. Shapiro, A., Swensen, C. (1969). Patterns of self-disclosure among married couples. Journal of Counseling Psychology, 16, 179-180.

35. Sillars, A.L., Weisberg, J., Burggraf, C.S., Wilson, E.A. (1987).

Content themes in marital conversations. Human Communication Research, 13, 495-528.

36. Silverman, P., Englander, S. (1975). The widow's view of her dependent children, Omega, 6(1), 3-19.

37. Smilkstein, G. (1988). The APGAR questionnaires - Screening for social support: Family, friends and work associates (unpublished manual).

38. Spielberger, C.D., Gorsuch, R.L., Lushene, R., Vagg, P.R. \& Jacobs, G.A. (1983). Manual for the State-Trait Anxiety Inventory (Form Y): Self-Evaluation Questionnaire. Palo Alto, CA: Consulting Psychologists Press.

39. Stearns, N.R. (1986). Factors affecting interpersonal communication as perceived by the spouse of the terminal cancer patient. Unpublished Master's thesis, University of Toronto.

40. Stern, M., Pascale, L. (1979). Psychosocial adaptation post-myocardial infarction: The spouse's dilemma. Journal of Psychosomatic Research, 23(1), 83-87.

41. Strauss, A., Corbin, J. (1990). Basics of qualitative research. Newbury Park: Sage Publications.

42. Thorne, S. (1977). The family experience. Cancer Nursing, 8, 223-228.

43. Turner, R.E., Edgley, C., Olmstead, G. (1975). Information control in conversations: Honesty is not always the best policy. Kansas Journal of Sociology, 11, 69-89.

44. Vachon, M.L.S., Freedman, K., Formo, A., Rogers, J., Lyall, W.A.L., Freeman, S.J.J. (1977). The final illness in cancer: The widow's perspective. Canadian Medical Association Journal, 117, 1151-54.

45. Vess, J.D., Moreland, J.R., Schwebel, A.I. (1985). An empirical assessment of the effects of cancer on family role functioning. Journal of Psychosocial Oncology, 3(1), 1-16.

46. Walster, E., Walster, G.W., Berscheid, E. (1978). Equity: Theory and research. Boston: Allyn \& Bacon.

47. Zahlis, E.H., Shands, M.E. (1991). Breast cancer: The partner's experience. Journal of Psychosocial Oncology, 9(1), 75-93. 